\title{
Antiplatelet and anticoagulation pretreatment in acute coronary syndrome: current guidelines and unresolved issues
}

\section{Irzal Hadžibegović*, Đeiti Prvulović, Krešimir Gabaldo, Ognjen Čančarević, Božo Vujeva}

General Hospital "Dr. Josip Benčević", Slavonski Brod, Croatia

\section{RECEIVED:}

February 9, 2016

ACCEPTED:

February 20, 2016

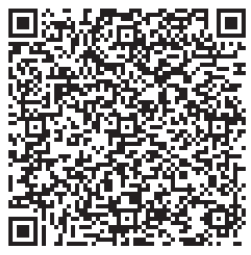

$\square$ Cardiologia Croatica 2016:11(3-4):106
KEYWORDS: acute coronary syndrome, dual antiplatelet therapy, anticoagulation therapy, pretreatment. CITATION: Cardiol Croat. 2016;11(3-4):106. | DOI: http://dx.doi.org/10.15836/ccar2016.106

*ADDRESS FOR CORRESPONDENCE: Irzal Hadžibegović, Opća bolnica "Dr. Josip Benčević", Andrije Štampara 42, HR-35000 Slavonski Brod, Croatia. / Phone: +385-91-533-3091 / E-mail: irzalh@gmail.com ORCID: Irzal Hadžibegović, http://orcid.org/0000-0002-3768-9134 • Đeiti Prvulović, http://orcid.org/0000-0002-8041-1197 Krešimir Gabaldo, http://orcid.org/0000-0002-0116-5929 • Ognjen Čančarević, http://orcid.org/0000-0002-1285-8042 Božo Vujeva, http://orcid.org/0000-0003-0490-3832

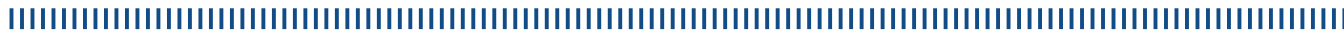

Background: Current evidence clearly show that patients with ST-segment elevation myocardial infarction (STEMI) should be pretreated with dual antiplatelet therapy (DAPT) and anticoagulation therapy immediately after confirmed diagnosis, and that pretreatment can be even performed safely prehospitally. ${ }^{1}$ In non ST-segment elevation myocardial infarction (NSTEMI), recommendations are not so clear, with data showing that pretreatment depends on what combination of DAPT is used and what is the risk profile of the patient. Also, less than $70 \%$ of all patients with NSTEMI undergo stenting after coronary angiography whereas the rest continue medical treatment or are scheduled for coronary artery bypass graft surgery. We present our data on anticoagulation and platelet antiaggregation therapy selection and timing in patients with STEMI and NSTEMI scheduled for early invasive approach, that were collected using our acute coronary syndrome flow chart, and compare them to current guidelines.

Patients and Methods: Standardized prospective flow chart was utilized to collect data on medical and interventional treatment of patients with STEMI and NSTEMI scheduled for early coronary angiography in 2016. Registry data from 2014 and 2015 were used as comparison.

Results: Data showed that all patients with STEMI received pretreatment with either clopidogrel (in 2014) or ticagrelor (in 2015 and 2016) and unfractionated heparin, but only in-hospital. Only aspirin was administered prehospitally. Patients with NSTEMI received enoxaparine, fondaparinux or unfractionated heparin, mostly before coronary angiography. Clopidogrel was administered before coronary angiography in all patients with NSTEMI in 2014 and 2015, whereas patients with NSTEMI in 2016 received ticagrelor, mostly before angiography. In 2016 there were nearly $10 \%$ of patients that were treated with ticagrelor after early coronary angiography, with no thrombotic complications.

Conclusions: STEMI pretreatment should be done as early as possible, and standardized protocols should encourage early detection and prehospital administration. NSTEMI protocols are however unclear, there are cases with unsupported mixing of anticoagulants before and during invasive treatment. Choice of antiplatelets and their timing of administration is still unclear in NSTEMI and requires further investigation.

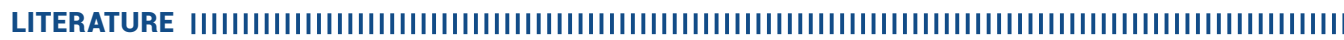

1. Sibbing D, Kastrati A, Berger PB. Pre-treatment with P2Y12 inhibitors in ACS patients: who, when, why, and which agent? Eur Heart J. 2015 Dec 27. pii: ehv717. DOI: http://dx.doi.org/10.1093/eurheartj/ehv717 